\title{
PCR detection of the Tth 111 I RFLP at the RB locus
}

\section{G.L.Vaughn, J.Toguchida, T.L.McGee and T.P.Dryja* \\ Taylor R.Smith Laboratory, Harvard Medical School, Massachusetts Eye and Ear Infirmary, 243 Charles Street, Boston, MA 02114, USA}

We previously identified and mapped a Tth 111 I RFLP within the human retinoblastoma locus $(1,2)$. Here we report oligomer sequences that can be used as primers to analyze this polymorphism using the PCR. This method yields results in as little as one day and does not require a radiolabelled probe.

PCR Primers:

Sense oligo 5'-ACCTTCCTAGCACTTAGACA-3'

Antisense oligo 5'-AAGGGCAAGAAACCAATAGA-3'

Polymorphism: Tth 111 I digest of the amplified fragment identifies two alleles. A1 = 1182 and $169 \mathrm{bp} ; \mathrm{A} 2=634 \mathrm{bp}$, $548 \mathrm{bp}$, and $169 \mathrm{bp}$.

Frequency: Allele frequencies were calculated from 136 unrelated individuals. $\mathrm{A} 1=0.12 ; \mathrm{A} 2=0.88$.

Chromosomal Localization: We have identified two Tth 111 I recognition sites within the 24th intron of the retinoblastoma susceptibility locus (13q14), $897 \mathrm{bp}$ and 1531 bp downstream of the $3^{\prime}$ end of exon 24 . The first site is invariant; the second site is polymorphic.

Mendelian Inheritance: Co-dominant segregation patterns were observed in 27 pedigrees with retinoblastoma (see figure for example).

PCR Conditions: We carry out PCR in a total volume of $50 \mu \mathrm{l}$ containing: $0.1 \mu \mathrm{g}$ of genomic DNA, 20 pmoles of each primer, $1.0 \mathrm{mM} \mathrm{MgCl} 2,200 \mu \mathrm{M}$ dNTPs, $50 \mathrm{mM} \mathrm{KCl}$, and $20 \mathrm{mM}$ Tris $\mathrm{pH}$ 8.6. The amplification is performed for 35 cycles with an annealing temperature of $50^{\circ} \mathrm{C}$. The amplified product is then passed through a $1 \mathrm{ml}$ Sepharose CL-6B column and digested overnight with Tth $111 \mathrm{I}$. DNA fragments are resolved by electrophoresis through a $2 \%$ agarose gel.

References: 1) Wiggs,J., Nordenskjöld,M., Yandell,D., Rapaport,J., Grondin,V., Janson,M., Werelius,B., Petersen,R., Craft,A., Riedel,K., Liberfarb,R., Walton,D., Wilson,W. and Dryja,T.P. (1988) New Engl. J. Med. 318, 151-157. 2) McGee,T.L., Yandell,D.W. and Dryja,T.P. (1989) Gene 80, $119-128$.

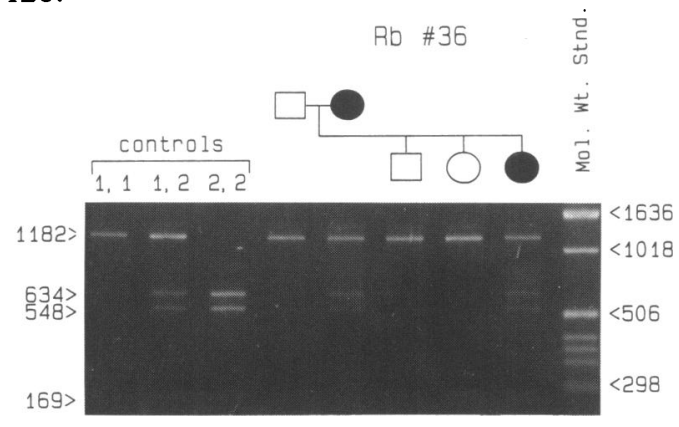

* To whom correspondence should be addressed

\section{Hincll polymorphism at the D10S95 locus}

\author{
Jingshi Wu and Kenneth K.Kidd \\ Department of Human Genetics, Yale University \\ School of Medicine, New Haven, CT 06510, \\ USA
}

Source/Description: KW29 (D10S95) is a recombinant bacteriophage $\lambda$ clone containing a $1.3 \mathrm{~kb}$ single-copy human insert and was isolated from a human chromosome 10 library constructed by the Lawrence Livermore National Laboratory in the HindIII site of the Charon 21 vector. The library (ID code: LL10NS01) was made available through ATCC (American Type Culture Collection).

Polymorphism: HincII detects a simple two-allele polymorphism with bands at either $9.0 \mathrm{~kb}$ (A1) or $1.7 \mathrm{~kb}$ (A2). No constant bands were detected.

Frequency: Estimated from 85 unrelated Caucasians.

A1: $0.42 \pm 0.04$

A2: $0.58 \pm 0.04$

Not Polymorphic For: BglII, EcoRV, HindIII, MboI and MspI in ten unrelated Caucasians tested.

Chromosomal Localization: Chromosome 10 origin of this clone has been confirmed by preliminary linkage data showing lod scores greater than 4 with each of the known chromosome 10 markers D10S22, CDC2, and D10S19 (1). These linkage data assign the clone to the region 10q21-q23.

Mendelian Inheritance: Co-dominant segregation of the HincII RFLP alleles was observed in five of our reference kindreds used for linkage studies (OA, TSCAN, TSORE, TSK, and TSM) with a total of 320 individuals.

Probe Availability: Freely available, contact JW or KKK.

Other Comments: RFLP pattern was observed under normal hybridization and washing conditions for a single-copy probe.

Reference: 1) Smith,M. and Simpson,N.E. (1989) Cytogenet. Cell Genet. 51, 202-225. 